\title{
FOCUS GROUP REPORT: MOBILITY AND EDUCATION
}

Chair: Raymond Morel, CPTIC, raymond.morel@techfaunige.ch

Rapporteur: Arthur Tatnall

Participants: Harri Ketamo (Finland), Timo Lainema (Finland), Jari Koivisto (Finland), Barbara Tatnall (Australia)

Key words: Mobile learning, mobile platforms, flexible learning, hand-held computers.

\section{INTRODUCTION}

The digitisation and convergence of media, communications, and Information Technology, and the advent of wireless computing, offers new possibilities for teaching and learning in all forms of education. In our initial discussions we agreed that although mobile technologies were a significant driving factor, the human issues concerned with the use of these technologies were a much more important consideration. Situations relating to mobility in education can be grouped into three categories:

1. People changing location but able to use ICT to gain access to the same information and facilities from the new location.

2. People equipped with mobile technology they can take with them, and so access information and facilities from other remote locations.

3. Mobile presence; the ability for a person to appear to be available at some remote location while really remaining at a base location.

Educators must remain interested in the development of mobile technologies, and also engage with the industry, because it may develop pedagogically inappropriate innovations. Constraints on using mobile technologies include costs, privacy, the need to ensure ethical use, and copyright laws. 


\section{USING MOBILITY IN EDUCATION}

Pedagogy, not technology, should drive the development of mobile technologies in Education. The group did not believe that mobile computing would, or could, replace traditional forms of learning in the future. However, it did see great possibilities for supplementing traditional forms and adding new educational possibilities. What other possibilities for these technologies exist in formal education or informal learning is not clear; issues of education versus training, teaching versus learning, studying versus learning and facts versus concepts/values need consideration. Enhanced learning could be realised in initial education, life long learning and corporate training, but differences between training (skills development) and education (meta skills) should be borne in mind. Important questions are: how might mobility help learning? what possibilities can mobility bring to education? Are there educational needs waiting to be fulfilled by mobile technologies, or will these needs be invented — and by whom?

The group sees mobile technologies as not only offering possibilities to do the same things in better ways, but also to do new things. It is characteristic of educational innovation that you cannot predict what will and will not work until you try things out and reflect on the pedagogy and practicalities. Students themselves might suggest these new possibilities when they gain familiarity with mobile systems. Issues of remote versus local teaching, synchronous versus asynchronous communication and working with individuals or groups are relevant here.

\section{EXAMPLES OF MOBILITY IN EDUCATION}

From a central location in northern Finland, a music teacher gives regular classes to students in a small primary school $85 \mathrm{~km}$ away using ISDN videoconferencing. The teacher plays the piano and acts as conductor of the school orchestra. The 0.5 -second delay between voice and picture causes some difficulty for the teacher, but it does not seem to lessen the pleasure of those playing in the orchestra. Another example used a 'web cam' in an art gallery. Students could use Bluetooth technology to set up short-term, ad hoc teams of anyone interested in a particular exhibit. Other examples include: access to 'real' situations, taking pictures of animals in a forest, expanding and updating knowledge databases, sharing actions between home and school, extending the capacity to be critical, increasing cultural understanding, forming virtual teams and creating personal portfolios. 


\section{RECOMMENDATIONS AND ACTIONS}

There is more to mobile learning than technology alone. It is recommended that consideration be given to all actors and to social, cultural and pedagogical impacts. At present there is no clear vision of how mobile computing could benefit learning, but this was considered preferable to having an educationally inappropriate vision. Concern was expressed of a need to offer expertise and services to manufacturers in the hope that they may work with us on projects. It is recommended that pilot programs, research and trials be encouraged and linked with curriculum development and teacher training. The group believes that mobile learning needs further investigation, as its potential educational impact is considerable. Means by which this might be achieved were identified, including: seeking links to other IFIP Working Groups and other Technical Committees to facilitate research, actively encouraging them all to focus on this topic from their perspective, setting up a reporting mechanism for developments, setting up a working conference on m-learning, setting up a professional group on mlearning at WCCE'05, asking TC3 to set up a Task Force on mobile learning.

\section{CONCLUSION}

Technological developments in ubiquitous and mobile computing offer possibilities to all levels of education and, due to their non-reliance on traditional communications infrastructure, they offer emerging countries an opportunity to jump ahead. Exactly how these technologies should best be used in education, however, is not completely clear at this time. It is important that further work be done in evaluating potential uses of mobile computing in education. This focus group recommends that TC3 set up a Task Force on mobile learning to conduct these investigations.

\section{REFERENCES}

Uther, Maria (2002). Mobile Internet Usability: What Can Mobile Learning Learn from the Past? IEEE International Workshop on Wireless and Mobile Technologies in Education August, Växjö, Sweden. 